\title{
Dialogic meaning construction and emergent reading domains among four young English language learners in second-language reading
}

Deoksoon Kim

\author{
Correspondence: deoksoonk@usf. \\ edu \\ Foreign Language Education and \\ Second Language Acquisition/ \\ Instructional Technology (SLA/IT), \\ Secondary Education Department, \\ 4202 East Fowler Ave, EDU 105, \\ Tampa, FL 33620, USA
}

\begin{abstract}
Rapid growth of English language learner populations has challenged teachers, particularly because English language learners' academic success and secondlanguage literacy are closely linked. Using qualitative research methods and verbal protocols, this study pursued two goals, namely examining English language learners' meaning-making processes as they engage in reading activities and how they construct meaning within particular contexts. Results document that dialogic responsive reading offers English language learners the zone of meaning construction for apprehending and mastering within and about domains. These English language learners adopted dialogic-responsive reading, relying on five domains: cultural, aesthetic, efferent, dialogic, and critical. These domains offer English language learners an evolving responsive reading strategy to develop secondlanguage literacy. These five domains are interwoven with the cultural knowledge, prior experiences, and performance styles of diverse learners to render the learning process more meaningful and effective. English language learners position themselves centrally, retaining their cultures' values, experiences, and perspectives while embracing new content and knowledge in the reading process.
\end{abstract}

Keywords: English language learner, Dialogic meaning making, Second-language literacy, Cultural knowledge

\section{Background}

Literacy is crucial to English language learners' (ELLs') academic success: It enables them to become active learners and social beings in an English-speaking culture (Cummins 1992). The rapid growth of the ELL population over the past decade (Peregoy and Boyle 2008) has demanded teachers' and administrators' attention and challenged them pedagogically. As the number of ELLs continues to rise, researchers continue to describe the challenges of learning to read in a first language (L1) and a second language (L2). ELL refers to learners who are learning English as their second language after learning a first language other than English (Stern 1983). Given the complex process of L2 reading, exploring L2 reading processes is demanding (Fitzgerald 1995; Koda 2007). Researchers agree that these processes are closely linked to academic success (August and Shanahan 2006; Cummins 1992).

Over the past decade, a convergence of state and federal policies has emphasized and institutionalized the teaching of reading and reading skills and subskills (e.g., phonemic

(c) 2011 Kim; licensee Springer. This is an Open Access article distributed under the terms of the Creative Commons Attribution License (http://creativecommons.org/licenses/by/2.0), which permits unrestricted use, distribution, and reproduction in any medium, provided the original work is properly cited. 
awareness, phonics, vocabulary; Pacheco 2010). Whereas some reading researchers argue that these skills and subskills are essential aspects of the reading processes (National Institute of Child and Health and Human Development [NICHD] 2000), others have strong concerns about teaching narrow skills-based reading approaches to ELLs (Olson 2007). Furthermore the main trend moves quickly to whole texts, empathizing reading fluency to enhance reading comprehension, whereas a more balanced approach may be more helpful to some students (Alexander and Fox 2004).

L2 reading appears to be a more complex process than L1 reading (Fitzgerald 1995): In their report on the National Literacy Panel, August and Shanahan (2006) demonstrated an urgent need to support ELLs ( language-minority students) in their rapid growth. They addressed ELLs' challenges in reading and writing well in English and indicated that the nation's K-12 schools, should urgently address the close link between ELLs' English proficiency and their empowerment and future success. They identified six key elements for ELLs' literacy development: (1) Key components of reading consist of phonemic awareness, phonics, fluency, vocabulary, and text comprehension (NICHD 2000). (2) High-quality instruction in the key components of reading boosts oral proficiency. (3) Oral proficiency and literacy in L1 facilitate literacy development in English. (4) There are important individual differences in L2 learning (i.e. general language proficiency, age, English oral proficiency, cognitive abilities, previous learning, and the similarities and differences between the first language and English). (5) Due to the challenges, better assessments for ELLs must be developed. (6) Finally, home language experiences have a positive impact on literacy achievement.

Initially, however, August and Shanahan (2006) stated that there little evidence of the impact of sociocultural variables in literacy achievement or development based on the panel's summary. In contrast, Cummins (2009) argued that sociocultural factors are significant in L2 learning in his review of August and Shanahan (2006), and Pray and Jimenez (2009) accepted Cummins' claim, which interestingly was against the Panel's recommendation. This important debate lead me to explore the involvement of social factors in L2 literacy and further discuss the uniqueness of ELLs' L2 reading.

It evolves from both the first and second languages and other factors such as linguistic differences between L1 and L2, cultural differences, and the particular context. Historically, the cognitive processes involved in L2 reading have been discussed with various foci. Studies have examined ELLs' language acquisition (Ellis 2008) and focused on textual components such as L2 vocabulary acquisition, grammatical structures, and the appreciation of L1 linguistic knowledge for L2 reading (Koda 2007; McElvain 2010). Some researchers have also focused on the interrelationship between L1 and L2, such as L1 positive transfer to L2 learning and how L2 reading skills transfer to L2 reading proficiency (Koda 2007; McElvain 2010; Yamashita 2002). Few studies, however, address L2 reading processes and dialogic meaning construction, critical areas for understanding L2 reading processes and vital for providing appropriate pedagogical recommendations. As Freire observed in 1970, ELLs are historical, cultural, social, and political beings, and L2 reading is a sociocultural practice (Perez 1998). L2 reading processes for English, however, have not yet been fully discussed and there is an urgent need to discuss ELLs' L2 reading processes in situated contexts (boundaries of dialogue in social contexts according to Bakhtin 1986). From a sociocultural perspective, reading is a vital system for communication and interaction (Perez 1998). 
The definition of literacy has evolved to encompass the entire process of thinking and meaning-making (Goodman 1987), which is how readers make sense of texts. Au (1993) extended the definition of literacy from mere reading and writing to include "the ability and the willingness to use reading and writing to construct meaning from printed text, in ways which meet the requirements of a particular social context" (p. 20). She emphasized the importance of the readers' willingness or feelings about reading and writing on the process, suggesting the reader plays a central role in the construction of meaning.

Goodman (1987) defined L1 reading traditionally as "meaning construction." Mortimer and Scott (2003) described the meaning-making process (interchangeable with meaning construction in this paper) as "dialogic in nature as the students try to make sense of what is being said by laying down a set of their 'own answering words' to the words of the teacher" (p. 122). Based on Dewey's (1933) philosophy, Krauss (2005) observed, "human beings have a natural inclination to understand and make meaning out of their lives and experiences" (p. 762), and reading (meaning making) occurs in "dialogic" ways (Bakhtin 1986). Reading is the purposeful construction of meaning within or about the situated context called dialogue (Bakhtin 1986), also known as communication or a semiotic exchange (Gee 2008). Johnson (2004) stressed that L2 learning can be explored socioculturally when the dialogic perspective of L2 reading is emphasized.

Furthermore, the U.S. "National Reading Panel Report: Teaching Children to Read" suggested effective reading instruction for children. Particularly, this document recommended the importance not only of practicing reading aloud, but also of teaching strategies to improve reading comprehension (International Reading Association 2002). The report's summary highlighted the effective instructional strategies of vocabulary and text comprehension (International Reading Association 2006).

This study investigated the L2 reading processes of four elementary ELLs, focusing on the interactions between the learners and various texts in situated contexts. Using qualitative and verbal protocols, I sought to elicit and examine ELLs' meaning-making processes. This study pursued two goals: the examination of (a) ELLs' meaning-making processes as they engage in reading activities focusing on learner's internal cognitive reading process and (b) how they construct meaning within the particular contexts (including such social factors as cultural background, personal experience, L1 and L2 literacy skills, and oral language proficiency).

To answer these questions, I reviewed the available contemporary literature on L2 reading, including the cognitive and social aspects of $\mathrm{L} 2$ reading. Next, I expanded the discussion to include the dialogic reading process.

\section{L2 Reading Research}

ELLs have various L2 proficiencies, cultural orientations, and cognitions, all closely related to age differences (Koda 2007; Stern 1983). Koda (2007) documented three major components of reading: (a) decoding (extracting linguistic information directly from print); (b) text-information building (integrating the extracted information into written form); and (c) reader-model construction (synthesizing the incorporated text information with prior knowledge p. 4). L2 reading obviously involves two languages. According to McElvain (2010), linguistic knowledge and prior knowledge help ELLs to 
construct meaning while engaging in reading events. ELLs' language proficiency (Koda 2007) and their L1 skills are directly linked to their L2 reading abilities (McElvain 2010). Cummins' (1992) exploration of the cross-linguistic relationship in reading skills demonstrated that $\mathrm{L} 2$ reading success depends primarily on L1 literacy competence. Related studies discussed the relationships between L1 literacy skills and L2 reading (McElvain 2010), L2 language proficiency and L2 reading (Koda 2007; Yamashita 2002), and L1 literacy skill and L2 proficiency's influence on L2 reading (Nassaji 2007). Likewise, prior learning experiences can be considered a reservoir of knowledge, skills, and abilities to be employed when learning a language and literacy skills (Koda 2007; McElvain 2010).

L2 reading is the product of word decoding, vocabulary knowledge, grammatical skills, and oral text comprehension (McElvain 2010). L2 proficiency with vocabulary and grammatical skills, however, appears closely linked to reading fluency and comprehension (McElvain 2010). Koda (2007) discussed the role of linguistic knowledge in text-information building, emphasizing syntactic awareness and text-structure knowledge. Word-recognition and decoding-skill studies showed that these skills cannot cover the full process of reading (Avalos 2003).

Researchers have documented contemporary L2 reading theory and reading strategies, but have not yet focused on the dialogic responsive reading process. Johnson (2004) emphasized that dialogic responsive reading is comparable to the sociocultural perspective in L2 learning. ELLs are at the centre of meaning construction, struggling to make meaning out of strange and foreign words, and their dialogic meaning construction must be closely observed and addressed.

\section{Dialogic Responsive Reading}

Dialogue is described as a, "give-and-take exchange of language between two individuals" (Uebel 2007, p. 331). Bakhtin (1986) saw the individual utterances in a dialogue as the junction between a speaker's specific speech intent and the listener's responsiveness; these two elements are constant and stable and create original meaningful linkages within the given boundaries. These two entities, speaker and active listener, create the true essence of meaning through purposeful exchanges. Bakhtin (1986) described dialogue as "The life of the text ... always develops on the boundary between two consciousnesses, two subjects" (p. 107), the author and the reader. Reading is an utterance within the given boundary, a kind of literacy work (Bakhtin 1986). The boundary can be a "rejoinder, letters, diaries, inner speech, and so forth" (p. 115). Bakhtin referred to reading as "an utterance" that creates brand new innovative meanings, claiming that the possibilities in the written word are utterly boundless.

The ELL who reads is as important as the author and is always central to meaning making, either obtaining knowledge, connecting to culture, engaging in lived-through experience (Rosenblatt 1978) reaching that deeper level of connection that generates readers' reading pleasure, dialoguing, or creating entirely new meanings from the reading (Bakhtin 1986; Freire 1970).

Within the L2-reading focus, responsive reading has been referred to under various names, for example, (Rosenblatt's 1978; 1986) efferent and aesthetic reading; Perez's (1998) literacy as a cultural practice, which means literacy makes sense within the given context; Bakhtin's (1986) reading as a dialogue; and Paulo Freire's (1970) critical 
literacy. These responsive readings demonstrate different foci of meaning making, but all represent a dialogue between the reader and the text in the situated context.

Rosenblatt's (1978) reader-response theory sees the reader as either gaining a livedthrough experience (interchangeably aesthetic) or obtaining information from the text (interchangeably efferent), which is how the ELL creates a dialogic relationship with the text. This relation could be efferent (informative) or aesthetic-transactions occurring with the text through the reader's lived experience, based on the reader's engagement with the text, which will reflect the reader's level of direct attention. Our individual experience is the sum of these transactions, and the continuous processing of these transactions is the ever-increasing enlargement of experience.

Dialogue, an invitation to think and produce meaning, is frequently referred to as dialogic thinking (Bakhtin 1986; Wells 2007). Dialogic thinking goes well beyond two people talking, essentially including any form of two-way semantic interchange between speakers, building a mosaic of new meaning among various texts (Hartman 1995), as well as between readers and texts (Rosenblatt 1978). When literacy is viewed as culturally and politically embedded cross-cultural communication (Freire 1970), the ELLs' cultural and political contexts become inseparable from utterances, content, style, and arrangement (Bakhtin 1986). ELLs' cultural and political contexts may differ from those of the text. L2 reading is also "a set of cultural practices and a product of cultural activity" (Perez 1998, p. 252). ELLs identify with words based on their understanding of the texts (Koda 2007), relying on their historical, cultural, and social backgrounds to understand the words.

Creative and critical thinking (Freire 2000) helps language learners develop awareness of others and value and appreciate differences. Such thinking also fosters constructive analytical skills, sensitivity to others, cultural and critical awareness of the self and others, and an evolving worldview (Freire 1970).

L2 reading praxis, reflective and active meaning creation through reading texts (Freire 2000), engages learners in learning language and in reading, analysing events and situations from various perspectives to understand how these perspectives position readers in the world. In this instance, reading is a core force of literacy and active learning; reading becomes a basic medium for evoking one's power in life (Freire 1970, 2000). Freire (2000) pointed to the re-creator concept of reading through the dialogic relationship between the author and reader: The ELL who reads becomes a rewriter, composing a new story while making meaning within the author's authority. L2 reading entails a critical perception of the world and the transformation of the world through practical action and reflection (Freire 2000). While reading, ELLs act as both reader and writer to create comprehension (Bakhtin 1986; Freire 2000).

These theories all clearly demonstrate the degree of dialogue and interrelationship among the reader, the text, and the context. Reading is a dialogic responsive process of meaning construction, with the reader responding to the text by creating a unique transactional moment in a particular time and space, the situated context (Rosenblatt 1978). All reading processes are closely linked to the boundary of dialogue and to the vital essence of dialogue. ELLs construct meaning by creating dialoguing with their past experiences and social interactions with others (Windschitl 2000). Learning to read and write are constituted as acts of knowing, reflected as values, or situated as discourse within a given cultural and social context (Gee 1996; Perez 1998). When 
considered as a dialogue focusing on the reflective process and meaning production, reading becomes a powerful, essential method of transformation whenever the reader encounters a new concept or constructs meaning from the word. Dialogic reading occurs in situated contexts in suitable domains.

\section{Domains as Peripheries of Situated Meaning}

Dialogue or reading requires a "boundary" with the text to make sense of it in a situated context (Bakhtin 1986; Gee 2008). Language and reading have particular meanings in any particular context (Rosenblatt 1978), a concept very similar to Gee's (2008) ideas on domains. Gee defined authentic learning in a domain as learning that "leads to growing mastery of the semiotic domain's design grammar and growing membership in its associated affinity group" (p. 139). For Gee (2008), design grammar is a set of principles or patterns that legitimate materials in the domain. The domain situates authentic learning (Lave and Wenger 1991), which is situated meaning (Perez 1998), as learners make sense of semiotic domains within the given contexts. Thus, within a domain, multimodalities (i.e., words, symbols) have meanings and combine together (Gee 2008). Gee also emphasized that learning is a trajectory for developing mastery status in the semiotic domains. By learning semiotic domains, learners can associate certain rules and content with affinity groups-groups of people associated within a semiotic domain. These individuals share a community of practices, a set of common goals, and subscribe to common values and norms (Lave and Wenger 1991).

\section{Methods}

This fifteen-month qualitative research involved four second- and third-grade ELLs in the same classroom at an middle-class, urban public elementary school in the southwestern United States. As a participant observer (Merriam 1998), I examined how ELLs constructed meaning. Using qualitative research (Lincoln and Guba 1985) as a general method, I inductively analysed the verbal protocol tasks and the interview data.

Verbal protocols captured the moments when thinking processes occurred (Ericsson and Simon 1993; Pressley and Afflerbach 1995). The main question of the protocols was based on a fundamental question-"What's on your mind?"-while the students were reading stories. Verbal protocols include think aloud (verbalized concurrently), introspection (verbalized with explanations of the readers' thoughts) and retrospection (verbalized immediately after the task; Ericsson and Simon 1993). Verbal protocols provide a window into ELLs' thinking process. The modified research method for this study sought a verbal report, but sought it in a method focused on comfort, a safe setting, in an open, friendly atmosphere for the young readers to vocalize their thoughts, minimizing any discrepancies between the ELLs' thinking process, vocalization, and language ability. The study's verbal protocols consisted of think-aloud and retrospective protocols.

\section{Setting and Nature of the Instruction}

Two language arts/literature classes provided the social context for this study: Ms. Green's language-arts and literature classroom for 10 months and Ms. Lopez's classroom for 5 months (all names are pseudonyms). Both were certified ESOL teachers and promoted interaction among students using small-group activities. Ms. Green, 
monolingual, always with a smile, promoted collaborative learning and scaffolding, encouraging students to work in groups and to help one another with questions. Her classroom was equipped with bilingual texts, dictionaries, and other hands-on materials for ELLs. Ms. Lopez, bilingual (Spanish and English), promoted bilingualism and various approaches and learning, while clearly recognizing that ELLs have many strengths. For example, her classroom had many Spanish vocabulary cards on its walls.

\section{Participants}

Using purposive sampling (Merriam 1998), I selected four second-grade ELLs, Hiroki, Jaewon, Maria, and Evert as participants for this study. The four ELLs had different first languages and cultures and had been learning English for under three years. These four ELLs lived near their school in lower-middle-class neighbourhoods.

Hiroki, a seven-year-old Japanese American, identified his main hobby as "doing chess." Ms. Green told me that Hiroki was an excellent problem solver and excited about creating new ideas. Hiroki spoke Japanese at home and had eighteen months of English experience, giving him an intermediate command of English. He was learning Kanji through a correspondence course at home with his mother.

Jaewon, a seven-year-old Korean American, was an exemplary second grader with a positive attitude toward his teacher, his peers, and his class. Though born in the United States, Jaewon spoke Korean fluently at home, so English was his L2 with three years of English education. His home environment contained various Korean books, songs, and decorations depicting "little Korea." When I tried to speak with his mother in English, she was not able to respond to me. Her English proficiency was that of a total beginner. I only spoke with her in Korean, and, throughout her interview, she expressed her concern about her poor English proficiency affecting Jaewon's academic progress. Maria, an eight-year-old Mexican American, learned Spanish as her first language. She had lived in the United States for 10 months when my research began. Fluent in Spanish, she was a beginner in English. Maria's mother was a competent bilingual who was born in the U.S. and came to Mexico at her age of 18. She had lived for 16 years in Mexico. Maria's mother reported that L1 knowledge supported her learning English as an L2, as Maria understood how to use language and language structures (Bigelow and Tarone 2004). She spoke Spanish at home and often used Spanish while reading stories and when she became excited.

Evert, a nine-year-old Swede, had come to the United States with his family just one week before I met him. A third grader in his school, Evert joined this second-grade classroom for the language arts and literature as a pull-out because the teachers were ESOL-certified. He was a total beginner in English. With his advanced L1 literacy skills, Evert's L2 English developed remarkably swiftly. In four months, he was able to read a first-grade book with only minor help.

I assessed each ELL's English proficiency based on the teacher's evaluations, their standard test scores (school diagnostic report, STAR reading, APS word-recognition placement inventory), various documents (spelling tests, math tests, quarterly tests, reading scores), and my own observations. I also assessed their L1 proficiency based on their parents' evaluations and my own 15 months of observations. L2 reading proficiency was measured by spelling tests and the school diagnostic report. 


\section{Materials}

The materials included culturally related and culturally unrelated content; I chose the selections for each ELL relative to his or her specific L1 cultural orientation, cognition, level of task, reading level, and English proficiency based on Bishop's (1993) culturalrelevance guidelines. The stories I defined as culturally related included the ELL's cultural concepts, ethnicity, cultural heritage, L1, events, and experiences. Although each ELL used various texts, this study's focus was not the ELLs' reading performance or on comparing the children's reading abilities. Rather, this study explored the children's dialogic responsive meaning construction.

The culturally related stories included Passage to Freedom for Hiroki, Woodcutter and Tiger Brother for Jaewon, I Hate English (related because the story involves coming to the United States) for Evert and Maria, Pettson and Findus for Evert, and Family Pictures for Maria. The culturally unrelated material included two depictions of Christopher Columbus (Follow the Dream and Encounter) and Hiroko Makes the Team for Hiroki and Jaewon, and Wilfrid Gordon McDonald Partridge for Evert and Maria. Personal experience, such as arrival in the United States, was classified as culturally related material for the ELLs. Since the ELLs were all from different countries and at various stages of English proficiency, it was not possible to use the same texts; instead, I chose the texts to fit each ELL, based on cultural criteria (Bishop 1993) and consultation with each teacher.

\section{Data Collection}

Multiple case studies and verbal protocols helped ensure the trustworthiness of the study's findings. I drew upon four sources of data concerning the ELLs' reading processes:

1. Observation: As a participant-observer, I visited the participants' classrooms once or twice a week for three or four hours each visit and collected field notes.

2. Interviews: During the research period, I conducted two interviews with each participant, their parents, and their teachers. Evert's mother participated as a translator in Evert's first interview and verbal protocol. After that, Evert was able to participate in other activities with minimal assistance from his mother.

3. Verbal-protocol reports: Each student conducted three verbal protocols, based on cultural orientation and English proficiency.

4. Documents: I reviewed the ELLs' classroom documents (reading responses, journals, and test scores).

The verbal-protocol sessions were conducted under my guidance. Verbal-protocol sessions included one training session and three protocols held in the classroom and home settings. The prompts provided after each session followed the retrospective-protocol guidelines. The prompts consisted of questions related to meaning construction ("Can you retell the story?") and dialogue and interaction between the story and the reader ("How do you feel after reading the story?"). In a typical think-aloud session, data gathered were the ELLs' reported immediate responses while reading (Davis and Bistodeau 1993) and their responses to the given prompts. Verbal reports demonstrated how each of these ELLs perceived their thought processes. 


\section{Data Analysis}

A systematic and rigorous analysis of the data followed a qualitative case-study data analysis. The twelve verbal reports were tape-recorded, transcribed, and analysed following the qualitative research analysis method (Lincoln and Guba 1985). Based on Creswell's (1998) data-analysis spiral, my analysis involved four stages: data management, reading and memorizing, describing and classifying, and representing and visualizing. In data management, I organized files and units of verbal reports manually, using index cards including protocol title, ELL's name, etc. Then I started making sense of the data, reflecting and writing notes. I read and reread the data, carefully coding it. After coding the data, I constructed categories while linking codes (e.g., culturally related, obtaining information; Corbin and Strauss 2007). While categorizing codes and discovering themes, I also reflected on my research questions in relation to the main focus of study-dialogic responsive reading. Themes and categories emerged inductively from the data.

For description and classification, I described the context, classifying and interpreting data using comparison. Finally, I visualized and represented the newly evolved themes (e.g., similar responses to culturally relevant texts: Maria and Evert responses after reading I Hate English). I also compared and contrasted the four participants' findings for the two beginners (Maria and Evert) and the intermediate and fluent ELLs (Jaewon and Hiroki). I also analysed other qualitative data, including transcribed interview data, observation notes, and reflective journals using the same procedure.

To ensure the trustworthiness of the study, I confirmed the answers with participants throughout the study. I also carried out peer debriefing and maintained a reflective journal (Lincoln and Guba 1985). Qualitative research is limited to specific cases and contexts. Participants' emic voices and thick descriptions from the cases, however, provided a detailed, rich account of the study's observations and insights (Lincoln \& Guba, 1985). Multiple data sets and analyses allowed triangulation to enhance trustworthiness and will allow the transfer of this study into various contexts of teaching and learning.

\section{Results}

As I focused on ELLs' meaning construction, several themes emerged from the data: (a) ELLs' cultural perspective; (b) ELLs' lived-through experiences; (c) ELLs' efferent reading; (d) ELLs' dialogic meaning construction; and (e) ELLs' critical reading to learn. To understand how ELLs make meaning while reading stories, it is vital to understand when, why, and how they work within or about these various domains.

\section{ELLs' Cultural Perspective}

Each ELL had a different first language, a different level of English proficiency, a different cultural background, and different prior knowledge-all reflected in their rich and diverse course-reading processes. The cultural perspective is derived from Lederach's (1995) definition of culture: "Culture is the shared knowledge and schemes created by a set of people for perceiving, interpreting, expressing, and responding to the social realities around them" (p. 9). Maria's case most clearly represented how beginner ELLs link their new learning to cultural knowledge and prior cultural experiences. Her cultural knowledge motivated her to read Family Pictures (Protocol 11). She identified 
closely with her culture and cultural experiences while reading Family Pictures, exemplifying how beginner ELLs refer to themselves while making meaning. While reading the "Birthday" chapter in Family Pictures, Maria spontaneously spoke and sang in Spanish:

They put you a little thing and they turn you around three times and they sing a little song that's kind of, 'Dale, dale, dale, pégale asina, porque si no le das pierdes el camino.' It's like 'hit it, hit it.' It's kind of hard to translate it. (Protocol 11)

Maria's cultural experiences motivated her to engage in this culturally related literacy event. Singing a song about the piñata, Maria evinced a high degree of transaction with these stories, and the transactional moment enriched her emotional connection to her father (in Mexico), saying "I missed him" with tears in her eyes. Her prior experiences gave her an emotional connection to the piece, helping her build context with her reading. All ELLs were very responsive in their reading when the contents are culturally related to them.

\section{ELLs' Lived-Through Experiences}

As beginning learners, Maria and Evert's cases revealed their lived-through experiences while reading I Hate English. Lived-through experience, derived from Rosenblatt's "aesthetic" reading, is related to how ELLs experienced their reading as a way of obtaining their pleasure. Thus, ELLs found "transactional" moment, which seems themselves in the story while reading (Rosenblatt, 1978). This aesthetic stance of reading enabled the ELLs to speak with strong voices. For example, Maria identified deeply with Mei Mei in I Hate English:

Because it's from another place. Hong Kong is another place from New York, so she wants to speak Chinese, and they want her to speak English, so she [Mei Mei] came here and [she] doesn't want to speak English, only wants to speak Chinese. (Protocol 10)

Maria used her personal opinions, culture, and experiences to identify the story's main ideas and to determine what was important in the text. She identified with Mei Mei's resistance to learning English and compared it to her own situation. Placing herself in Mei Mei's situation, Maria agreed with Mei Mei: “No. Mei Mei doesn't speak English because she wants to speak Chinese. But everybody is bugging her because they want her to speak English. And she wishes she was in Hong Kong" (Protocol 10). Maria understood why Mei Mei did not want to speak English: "Because it's not her main language."

Evert also dialogically connected to himself, using his L1 literacy skills, asking questions and monitoring his comprehension while reading I Hate English and Pettson and Findus. His most used skills were his connection to self and rhetorical strategies, which transferred well from his L1 (Bigelow and Tarone 2004). Like Maria, Evert also identified with Mei Mei's struggles, and frustration. He stated, "Yeah, I know how she feels. I felt the same thing as her when I came to a new country" (Protocol 6). Dialoguing with Mei Mei, Evert became part of the story with her, connecting his cultural 
experiences to hers. Evert understood Mei Mei's situation through his own situation, by reflecting on his lived experience (Rosenblatt 1978). He also recommended building the community and demonstrated his aesthetic stance by proposing that a friend read the story: "I want to ask a friend to read this book. So they can understand how I feel" (Protocol 6).

Evert connected deeply with Mei Mei's personality and experience as an English beginner in the United States, demonstrating total transaction with Mei Mei through her language struggles and reflecting on his own experience. Having time to understand the context with the other (Mei Mei in this instance) was very important for Evert. He felt safer, not so alone, having shared Mei Mei's experiences through the reading process. Reflecting his engagement, he evaluated the story with "She [the author] has done a good book" (Evert's interview). Evert clearly believed that sharing this story with his friends would show them his situation in his new country.

\section{ELLs' Efferent Reading}

The four ELLs developed their vocabularies, syntax, and concepts through reading. For all ELLs, the reading process provides new information and knowledge. For example, Hiroki attained the new word visa in the context of Passage to the Freedom. He understood the word as "And he has to, like, sign everybody's-I don't know how to read that word [visa]" (Protocol 1). Hiroki did not know how to read the word, but understood a meaning in context: "I kind of figured out. It was, like, this piece of paper that he [ambassador] would sign. Like, the part, like, he signs those pieces of papers that help those other people from, like, getting killed and stuff" (Protocol 1). Hiroki discovered the meaning of the word "visa" from the context of the story.

Maria tried to grasp the main ideas, as well as the main words of the stories by using simple words such as the race, Chinese and Hong Kong, and fair and piñata to point out the main ideas and significance of the story. Evert identified a memory as "Something very sad or something happy," adding his own perspective after reading Wilfrid Gordon McDonald Partridge (Protocol 12). Defining complicated or key words (e.g., memory) appeared to be an important step in obtaining new information. Evert said he knew the word "memory" in Swedish, so he comprehended the word in English without any effort.

Similarly, the learners derived lessons from the stories. For example, after reading Hiroko Makes the Team, Jaewon observed, "The important part is, be nice to each other-Never make fun of other people when they couldn't. You just need a lot of practice [to win swimming race.] That's all" (Protocol 3). As they reflected on the stories, new ideas emerged. Hiroki identified the main ideas, figured out the significance of the story, and related the text to his own beliefs. Hiroki's schema from the content and format of the text was clear. Hiroki also obtained new information by identifying main ideas such as "Friendship" in Encounter (Protocol 5), "I think when the dad [ambassador] starts to help people" in Passage to Freedom (Protocol 1), and "So you can read maps to go somewhere" in Follow the Dream (Protocol 8).

\section{ELLs' Dialogic Meaning Construction}

ELLs constructed meaning as they read. Jaewon's case is a good example of this dialogic reading process. I observed his strong links to personal preferences, experiences, 
intertextuality, and cultural orientation (Hartman 1995). Jaewon's intertextuality developed a mosaic of the text, using his cultural background knowledge, textual knowledge, and world knowledge. His inferential skills also supported using his cognition and knowledge processing while reading, invoking his dialogic thinking experiences.

Jaewon often summarized and synthesized the story to evoke dialogic responses and to centre himself in the reading event. For example, Jaewon used $\mathrm{O}$ for positive and $x$ for negative to evaluate the story: "This [Encounter] might be also $\mathrm{O}$ or $\mathrm{X}$, and this one [Follow the Dream] would be O 'cause this has landing information, and this just has traveling information, and it's just different." He continued, "Like moving, so if you combine these two books [Encounter and Follow the Dream] together, like this [showing me the two books overlapped], they would know that it's Christopher" (Protocol 9). As a synthesizer, Jaewon addressed Columbus's identity by combining both perspectives (Encounter was based on the Native American perspective while Follow the Dream was based on a European perspective). These verbal reports exhibited Jaewon's dialogic response to the two conflicting characterizations of Christopher Columbus.

Jaewon continually created critical points of view based on his theory building, sociocultural values, and prior knowledge. He dialogued with texts and became a rewriter when reading stories, creating new viewpoints on the story following the author's spirit. For example, Jaewon represented the two authors' intentions and purposes after reading the two versions of the Christopher Columbus story by stating, "These are different! Are they same? No!" (Protocol 4).

\section{ELLs' Critical Reading to Learn}

To construct meaning from reading through a critical lens, Hiroki and Jaewon were constantly questioning and evaluating the stories. Hiroki frequently identified important ideas, determining significance and evaluating the content of the stories. Having determined the important ideas, Hiroki admired Columbus's adventurous personality while reading the European perspective on Columbus in Follow the Dream:

I thought that he was pretty brave to go see-to go around the world. To the other side of-This book [Follow the Dream] is more informative and this more data orthis [Encounter] is part of a different story about this event. (Protocol 8)

As examples of Hiroki's explorations, these two different perspectives on the same story are particularly valuable. After reading Follow the Dream (Protocol 8) and seeing Columbus as the "hero" who discovered America, Hiroki said, "I learned that [Columbus] discovered the-he, like, helped the world, because they all thought that the world was flat and they thought-they didn't know America." While reading Encounter (Protocol 5), written from the Native American perspective, however, Hiroki considered the concept of invader. Hiroki's response shifted to the opposite stance while reading the Native American perspective in Encounter. “Different. [Encounter] doesn't say anything about-Christopher Columbus [depicted as an "explorer" in this story] It doesn't say the word anywhere. I think [Christopher Columbus] shouldn't. Not the land, just the [Native] American people" (Protocol 5), expressing his objection to Christopher Columbus's landing in the Western Hemisphere as an invader. Hiroki stated, "They shouldn't come to America without [Native American's] permission” (Protocol 5). 
Through on-going dialogue, Hiroki discovered the main ideas of the stories and further developed critical thinking skills. He dialogued with himself to understand the two different perspectives and developed his own understanding of Columbus. Evaluating the historical event, Hiroki comprehended the story Follow the Dream (Protocol 8) from an efferent domain, and he developed empathy as he read Encounter (Protocol 5). Hiroki proposed that his friends read both books to know Christopher Columbus thoroughly.

\section{Discussion}

All the findings revealed ELLs' responsive reading processes and meaning construction. ELLs' responses to the text were highlighted as particular or multiple domains. It's vital to understand how domains are relevant to the research context and to the results. Based on the findings from the study, three discussions follow: (a) L2 responsive reading domains; (b) L2 meaning construction through emergent domains; and (c) pedagogical implications.

\section{L2 Responsive Reading Domains}

These ELLs identified with the stories closest to their cultural schema, experiences, and social values. They tended to evaluate stories as deeply interwoven into their cultural heritage, first language, values, and beliefs. The beginner ELLs, Maria and Evert, favoured culturally related texts, while the intermediate and fluent ELLs, Jaewon and Hiroki, connected to culturally unrelated texts through responsive reading processes (Kim 2009a, b).

Maria and Evert seemed to feel safe and empowered while reading stories related to their cultural backgrounds and personal experiences. For example, Maria, a mostly quiet student, sang a song with enthusiasm. Evert appeared to be empowered after having read I Hate English, recommending that his classmates also read the text. "They [classmates] will understand me better."

Domains provide ELLs with precursors to support their learning and to engage in the learning process. L2 dialogic reading responses were connected to the readers themselves and to the texts. Maria and Evert made strong connections with their cultural knowledge and experiences, making sense of the text by taking a cultural domain that elicited empathy with the text. They invited friends to read cultural-experience stories (I Hate English), whereas Hiroki and Jaewon promoted Encounter and Follow the Dream. Jaewon and Hiroki, more advanced ELLs, were more connected to both culturally and not culturally related stories.

Critical reading also stimulated their thinking skills as a bridge to critical and dialogic thinking (Bakhtin 1986; Wells 2007). Jaewon and Hiroki not only understood how they thought and used strategies while reading, but also how they demonstrated their dialogical thinking skills (Bakhtin 1986) with the not culturally related texts. Hiroki and Jaewon's complex set of cognitive structures clarified information about events and the contents of the story, drawing upon their cultural knowledge and prior experiences (Anderson 1994). Jaewon and Hiroki comprehended the story's content, comparing and contrasting their pre-existing knowledge to acquire new information. Further, English proficiency seemed an important means for connecting with not culturally relevant texts: as the readers tried to connect to what they were reading, they found themselves having to become more proficient with English. 


\section{L2 Responsive Reading Through Emergent Domains}

Results showed ELLs to be active knowledge builders and critical thinkers. In terms of reading as a form of dialogue, culturally related texts empower ELLs, allowing them to establish strong connections to social values evident in the texts, whereas not culturally related texts offer dynamic discourse and creation through the reading process.

Dialogic talk is the key to embedding and expanding these experiences (Rosenblatt 1978). Thus, learning always requires domains in situated contexts. While ELLs make meaning from text within the domains or about domains, the reader actively responds to the text, and these processes motivate ELLs' meaning construction while reading; this transactional process impacts the readers.

The domain provides the zone for learners willing to participate and who have the motivation to engage in extended practice within the domain and who are willing to experience "a way that they take on and grow into a new socially-situated identity, an identity that they can see as a fruitful extension of their core sense of self" (Gee 2008, p 147). Within the domains or about the domains, ELLs retain a "core sense of self," which means that ELLs transform their sense of their own unique individual traits and history. Their identity reflects their ways of acting, interacting, symbols, and so forth. This event becomes a certain means of understanding, constructing meaning, and dialoguing with the text (Kim 2011).

Based on the results, five domains emerged. ELLs situate themselves in five domains-(a) cultural, (b) lived-through (interchangeably aesthetic), (c) efferent, (d) dialogic, and (e) critical-to construct meaning and to enhance their experience while engaging in reading activities. Apparently the five major semiotic domains for the responsive reading process discussed here are related to such prior theories as Carrell's (1988) schema theory, Rosenblatt's $(1978,1993)$ reader-response theory, and, especially, Bakhtin's (1986) dialogue and Freire's (1970) critical consciousness, because all the domains are grounded in the dialogic principle.

The study's results showed how ELLs master certain reading texts, associate with cultural norms and values by affinity group, and successfully construct meaning within multiple domains. The five domains emerging through the study are: the cultural domain, which ELLs connect to their cultural background knowledge and traditions; the efferent domain, through which ELLs obtain information; the aesthetic domain, in which ELLs transact with the story through emotional associations; the dialogic domain, in which ELLs query and dialogue with the story as readers such as through questions to earlier and later selves and to the author (Bakhtin 1986); and the critical domain, where ELLs think critically and become rewriters of the story as readers (Table 1). These domains can be useful for enhancing educators' awareness of L2 responsive reading processes. All domains offer ELLs rich dialogic opportunities.

These five dialogic domains emerging from the data emphasize the role of the ELL in reading processes. Rosenblatt defines stance as a continuum-private, public, or mixed (Rosenblatt 1986). A stance determines "whether selective attention will focus predominantly on the public, lexical aspects of meaning, or whether the focus will broaden to permit attention to the matrix of personal overtones, kinaesthetic states, intellectual or emotional associations" (Rosenblatt 1986, p. 124). Specifically, each domain allows the reader's selective attention to identify and transact with the text in private, public, or mixed stances. 
Table 1 Emerging Dialogic Reading Domains: Cultural, Efferent, Aesthetic, Critical, and Dialogic

\begin{tabular}{|c|c|c|}
\hline Domain & Stance & Example \\
\hline Cultural & $\begin{array}{l}\text { Private aspect of } \\
\text { meaning }\end{array}$ & $\begin{array}{l}\text { Maria's evocation while reading Family pictures. She sings the song about } \\
\text { the piñata. }\end{array}$ \\
\hline Efferent & $\begin{array}{l}\text { Public aspect of } \\
\text { meaning }\end{array}$ & $\begin{array}{l}\text { Hiroki's and Jaewon are gaining information about Christopher } \\
\text { Columbus's adventure story and Evert's new vocabulary. }\end{array}$ \\
\hline Aesthetic & $\begin{array}{l}\text { Private aspect of } \\
\text { meaning }\end{array}$ & Evert's and Maria's reading processes while reading I Hate English. \\
\hline Dialogic & $\begin{array}{l}\text { Private and public } \\
\text { aspect of meaning }\end{array}$ & $\begin{array}{l}\text { Hiroki's and Jaewon's responses while reading Follow the Dream and } \\
\text { Encounter: The two different depictions of Christopher Columbus drive } \\
\text { from the authors' different intention. }\end{array}$ \\
\hline Critical & $\begin{array}{l}\text { Private and public } \\
\text { aspect of meaning }\end{array}$ & $\begin{array}{l}\text { Jaewon's and Hiroki's exploration of the two versions of Christopher } \\
\text { Columbus (Encounter and Follow the Dream). Hiroki said Christopher } \\
\text { Columbus should not invade the Native Americans. }\end{array}$ \\
\hline
\end{tabular}

These dialogic responsive domains embrace the stances, which are sometimes combined. As previously stated, domains provide a zone for the ELL's active participation and engagement, ultimately creating situated meanings and gaining a membership in affinity groups. Authentic learning occurs while ELLs simulate the perspectives in order to attain situated meanings of semiotic domains within the context of their reading.

Alternatively, the domains may stand alone while reading and focus the reader's attention. This selective attention and situated meaning determine the results of reading comprehension and further develop agency of reading and learning. Gee (2008) pointed out that "each of them is associated with a group of people who have differentially mastered the domain, but who share norms, values, and knowledge about what constitutes degrees of mastery in the domain" (p. 138). The reader may work in all five domains simultaneously, or in a particular domain at a particular time, with a particular text, or within certain contexts.

Through reading, the reader chooses "a selective attention" which means readers are constantly choosing this particular attention in order to master a set of practices, common goals, endeavours, values, and norms by moment-to-moment transaction with the text (Rosenblatt 1978). Examples from this study are Hiroki's and Jaewon's responses while reading the two depictions of Christopher Columbus. To evaluate and synthesize the two stories, both boys primarily used the critical and dialogic domains, or a mixture of the two.

The four ELLs embedded comprehension, sensations, images, feelings, and emotional and intellectual associations. All readers reflect, interpret, find main ideas and details of stories if necessary, evaluating, questioning, and criticizing by choosing and mixing among various domains. ELLs were interacting with the cultural, efferent, aesthetic, critical, and dialogic domains.

\section{Cultural domain}

A cultural domain offers the reader self-recognition as well as a connection to cultural knowledge, experiences, and beliefs while reading stories. All ELLs embrace the values, experiences, and perspectives of their own cultures and cultural experiences even as they expand into others. The cultural domain facilitates comprehension and transaction with the text. Maria and Evert, for example, worked extensively in this domain. After reading the Birthday chapter in Family Pictures, Maria burst into song while 
explaining the piñata, fondly recalling her father who was absent. Maria's spontaneous singing demonstrated her engagement with the story and her ownership of learning (Cummins 1992). Maria and Evert used their cultural domain while reading I Hate English and further developed the agency of reading. They recommended that their classmates read this text to build their learning community. All ELLs used cultural domain frequently and spontaneously. Beginner ELLs such as Maria and Evert engaged in the reading event and related to the culturally related text effortlessly and with enthusiasm.

\section{Efferent domain}

The efferent domain facilitates obtaining new knowledge and is primarily involved with analysing, abstracting, and accumulating what will be retained after the reading. This domain seemed to relate to L1 reading ability closely to L2 reading (Koda 2007; Yamashita 2002). For example, Evert, a total beginner, was able to identify the main idea and key words (e.g., memory) of Wilfrid Gordon McDonald using his L1 literacy skill. He already knew the word for "memory" in Swedish. This information helped him to comprehend the story easily. Despite of his low L2 proficiency, he readily identified the genre and plot of the story. All four ELLs sought information within this domain, implicitly acknowledging the power of knowledge, from simple vocabulary to complex information.

\section{Aesthetic domain}

In the aesthetic domain, the reader's attention is focused primarily on experiencing what is being evoked, the lived-through experience, with private aspects of meaning attended to during the reading (Rosenblatt 1978). This domain is closely associated with emotion, sensation, and feelings. For example, Maria and Evert transposed Mei Mei's feelings with their own while reading I Hate English. They temporarily became Mei Mei.

\section{Dialogic domain}

Bakhtin (1986) insisted that meaning comes into existence only when two or more voices interact: When the voice of a listener (reader) responds to the voice of a speaker (author). Reading is an on-going process; readers not only comprehend, question, and evaluate the text, but also create new meaning from the text and create and share their new knowledge with others. During L2 literacy acquisition, readers dialogue in various ways: between their social values and prior experiences, between L1 skills and L2 proficiency, by themselves, between texts (intertextuality), and in the social world (Koda 2007; McElvain 2010). Dialogic also involves dialogue between an L1 and an L2 self, a process that helps ELLs to recognize themselves, to co-construct meaning while reading, and to become social beings in their new culture (Bakhtin 1986).

Bakhtin's (1986) dialogic discourse was embedded in the study as I analysed the data and reconstructed the participants' voices. Jaewon and Hiroki dialogued by themselves-between an earlier and a later self (Bakhtin 1986)-and with the text in their active understanding of two different perspectives of the same historical event. Jaewon and Hiroki used dialogic thinking skills as bridges to culturally unrelated texts. Within this domain, they played active roles in meaning-making processes. Dialogic domains appeared to provide praxis of action and reflection (Freire 1970).

\section{Critical domain}

Literacy enables one to read the world and build critical consciousness; to perceive social, political, and economic oppression; and to take action against the oppressive 
elements of society (Freire 1970). Hiroki and Jaewon co-constructed meaning while reading without violating the spirit of the work. This domain is the creation of meaning with the reader co-constructing public and private aspects of meaning from the text. ELLs, as historical, social, cultural, and political beings, create their critical consciousness to read and understand the text in its context (Freire 1970).

While reading Follow the Dream, Hiroki considered two concrete facts: Christopher Columbus discovered America from the European perspective, but from the Native American perspective, Columbus was an invader who came to America without permission. Hiroki's dialogue indicated that he associated with Follow the Dream, emphasizing Columbus's discovery, but he also acknowledged the concept of invader, realizing that Christopher Columbus was not an expected or "invited" guest, reflecting Encounter.

\section{Conclusion and Pedagogical Implications}

ELLs make meaning while reading stories within the domains or about the particular domains, depending on the texts at hand. While ELLs make meaning of the situated contexts (Gee 2008), these domains embrace these four ELLs' ethnic and cultural heritages, L1 literacy, and real-life experiences, acknowledging them as active knowledgegenerators who co-construct meaning from the text (Bakhtin 1986; Freire 1970). Employing certain domains also increases the critical thinking skills and degree of dialogue among ELLs, with the texts and within social contexts, appropriately implementing proper domains under each circumstance (Bakhtin 1986; Freire 1970; Perez 1998; Wells 2007). ELLs are situated in a learning community (Lave and Wenger 1991), playing the "role" of a "certain kind of person", shifting their "socially situated identity" through the construction of meaning (Gee 2008; Kim 2009b).

In line with Koda's (2007) explanation of ELLs' uniqueness, the ELLs in my study apparently used two languages and cultures to construct meaning while reading. It is vital to apply these factors in our daily teaching. The uniqueness of ELLs' comprehension of texts appeared in the four examples. First of all, ELLs use both of their languages and their reading processes developed from intertwined knowledge and experiences from the two languages and cultures. As August and Shanahan (2006) indicated that ELLs, "take advantage of cognate relationships between their first language and English to understand English words, an important precursor to comprehension" (p. 5). Maria's case clearly demonstrated how she used her knowledge of the Spanish piñata to explain to me in English. Evert also used his Swedish skill to understand memory. Secondly, ELLs also extend their meaning construction further to develop their critical thinking as interweaving and testing these two languages (e.g., Jaewon's and Hiroki's cases). Third, ELLs developed their ownership of learning as connecting to their L1 culture and personal experience of arriving in the new country (e.g., Maria's and Evert's cases). Fourth, their oral proficiency (e.g., Maria's case) seems also crucial to developing their L2 practice. It is very important to understand these processes; teachers need to encourage ELLs to use their first and second languages as well as both cultures as part of their L2 practice.

Teaching ELLs to practice and use these domains will maximize the benefit the reader derives from the reading process. Rosenblatt (1993) stated, "for a historical work or a political speech that uses many so-called literary devices, it will be especially 
important to decide what major stance to adopt" (p. 383). There is not a single "correct interpretation," but the open-minded admission of several points of view. The 2002 conclusion from the International Reading Association clearly stated that "when readers are given cognitive-strategies instruction, they make significant gains on measure of reading comprehension over students trained with conventional instruction" (p. 13). The panel also emphasized that teaching a variety of reading-comprehension strategies in contexts and content areas leads to increased learning of these strategies. It is vitally important for teachers to understand these domains to teach various reading strategies. Teachers need to understand how ELLs connect to the text and comprehend it using various strategies within the domains (Park and Kim 2011). Providing and practicing these domains is crucial. By being familiar with these domains, ELLs will be ready to comprehend the texts.

As the panel recommended, more intensive instruction and modelling, employing effective instruction, and transactional practices derived from research are more successful in improving reading and connecting ELLs to the texts and lead them to be academically successful (August and Shanahan 2006; Kim 2009b). Within the domains or about the domains, students develop ownership of learning and develop their dynamic identities (Kim 2009a). These dialogic responsive reading domains will be helpful in obtaining content knowledge in all the subjects and skills routinely taught in schools and in enabling students to create their own ownership of learning and willingness to learn (Au 1993), reflecting the power of literacy (Freire 1970).

Using think aloud protocol, we practice these domains with ELLs. I provided simple samples of questions while stimulating the ELL's reading processes. As the summary of International Reading Association (2002) concluded, teachers are encouraged to explain specific strategies to enhance each domain and model them for students. These strategies improve students' reading comprehension. Teachers were encouraged to model their own thinking processes and to stimulate students to ask questions and discuss possible answers among themselves. These responsive domains keep students engaged in their tasks and demand active involvements, as well as ongoing thinking.

Practicing these responsive reading domains is fundamental for adopting them. According to Gee (2008), ELLs learn better when they use and develop precursors (interchangeably necessary skills, knowledge, and/or social languages), which facilitate becoming a member of the affinity group. For example, ELLs drew upon their own cultural knowledge to make sense of a cultural domain. Using culturally meaningful or familiar reading materials that provide strong precursors also appeared to facilitate reading comprehension (August and Shanahan 2006). Consequently, ELLs apprehend and master this domain without difficulty, since they have a well-developed precursor. To master critical and dialogic domains, ELLs need to practice several precursors such as cultural domain, critical thinking, and so forth. This networking is crucial for schooling and language learning. Practicing these domains using think-aloud teaching protocols (Weaver 2002) must be embedded in daily teaching, fostering cultural continuity and critical consciousness (Freire 2000). Situating meanings requires personalized experience of a domain and the ability to situate meaning in the terms of that experience (Gee 2008). Praxis is crucial to mastering content and concepts, and becoming members in or about the domains. Domain praxis is based on genuine dialogue with learners, accepting and valuing their own voices, sharing their cultural and historical 
knowledge and experiences, and inquiring into their reading of the word and the world, recognizing that the readers are rewriters (Bakhtin 1986). Rewriting the text as a ELL entails a critical perception of the word and the transformation of the world through practical action and reflection (Freire 1970; 2000).

Cultural, aesthetic, and efferent domains empower ELLs and will expand their own learning, as they become competent and confident learners. Critical and dialogic domains transform knowledge so that ELLs can read any text (culturally or not culturally related) by forging a connection with it. By scaffolding their knowledge with capable peer support, ELLs can grow into cooperative partners (Vygotsky 1978). Educators are cultural workers promoting dialogic thinking to create bridges to critical thinking (Freire 1970; 2000). Educators should encourage ELLs to share their cultural strengths with others in the mainstream classroom. With this guidance, ELLs will be empowered to read words and competently to read the world.

\title{
Endnotes
}

This is a part of the larger study. This study used only eight protocols: Protocol 1 (Jaewon reading Woodcutter and Tiger Brother), Protocol 4. (Jaewon reading Encounter), Protocol 5 (Hiroki reading Encounter), Protocol 8 (Hiroko reading Follow the Dream), Protocol 9 (Jaewon reading Follow the Dream), Protocol 10 (Maria reading I Hate English), Protocol 11 (Maria reading Family Pictures), and Protocol 12 (Evert reading Wilfrid Gordon McDonald Partridge).

\section{Abbreviations}

ELL: English Language Learner; L1: First Language; L2: Second Language

\begin{abstract}
Acknowledgements
I am thankful to Dr. Suresh Canagarajah at Pennsylvania State University for his thorough review of my first draft. I am also deeply grateful to Dr. Jane Applegate at the University of South Florida for her steadfast support throughout the
\end{abstract} writing process. All errors and omission are my own.

\section{Author's information}

Deoksoon Kim is an Assistant Professor of Foreign Language Education and Second Language Acquisition and Instructional Technology at the University of South Florida and an iTeach Fellow at USF. Her research involves second language and bilingual processes from a sociocultural-constructivist perspective, L2 reading and literacy, integrating instructional technology in teacher education, and ethnic minority students. She has published in Computers and Education, English Leadership Quarterly, TESOL Journal, Journal of Reading Education, TESOL publications, a Research Anthology chapter sponsored by AERA, and elsewhere. She delivered keynote speeches at the International Qualitative Research Conference in 2007 and 2010.

Competing interests

The author declares that they have no competing interests.

Received: 7 June 2011 Accepted: 16 December 2011 Published: 16 December 2011

References

Alexander, PA, and E Fox. 2004. A historical perspective on reading research and practice. In Theoretical models and processes of reading, 5 edition. ed. Ruddell RB, Unrau NJ. 33-68. Newark, DE: International Reading Association.

Anderson, RC. 1994. Role of reader's schemata in comprehension, learning and memory. In Theoretical models and processes of reading, 4 edition. ed. Ruddell RB, Ruddell MR, Singer H. 469-482. Newark, DE: International Reading Association.

Au, KH. 1993. Literacy instruction in multicultural settings. Fort Worth, TX: Harcourt Brace.

August, D, and T Shanahan. 2006. Developing literacy in second-language learners: Report of the National Literacy Panel on language-minority children and youth. Mahwah, NJ: Lawrence Erlbaum Associates.

Avalos, MA. 2003. Effective second language reading transition: From learner specific to generic instructional models. Bilingual Research Journal 27: 171-205.

Bakhtin, MM. 1986. Speech genres and other late essays (trans: McGee, WW). Austin: University of Texas Press.

Bigelow, M, and E Tarone. 2004. The role of literacy level in SLA: Doesn't who we study determine what we know? TESOL Quarterly 39: 689-710. 
Bishop, RS. 1993. Multicultural literature for children: Making informed choices. In Teaching multicultural literature in Grades K-8, ed. Hanis VJ. 37-53. Norwood, MA: Christopher Gordon.

Carrell, PL. 1988. SLA and classroom instruction: Reading. Annual Review of Applied Linguistics 9: 223-242.

Corbin, JM, and AL Strauss. 2007. Basics of qualitative research: Techniques and procedures for developing grounded theory. Thousand Oaks, CA: Sage.

Creswell, JW. 1998. Qualitative inquiry and research design: Choosing among five traditions. Thousand Oaks, CA: Sage.

Cummins, J. 1992. Language proficiency, bilingualism, and academic achievement. In The multicultural classroom, ed. Richard-Amato PA, MA Snow. 16-26. New York, NY: Longman.

Cummins, J. 2009. A book review on literacy and English-language learners: A shifting landscape for students, teachers, researcher, and policy makers. Educational Researcher 38(5): 380-381.

Davis, JN, and L Bistodeau. 1993. How do L1 and L2 reading differ? Evidence from think aloud protocols. Modern Language Journal 77: 459-472.

Dewey, J. 1933. How we think. New York: Heath Books.

Ellis, R. 2008. The study of second language acquisition. New York: Oxford University Press.

Ericsson, KA, and HA Simon. 1993. Protocol analysis: Verbal reports as data. Cambridge, MA: MIT Press.

Fitzgerald, J. 1995. English-as-a-second-language learners' cognitive reading processes: A review of research in the United States. Review of Educational Research 65: 145-190.

Freire, P. 1970. Cultural action and conscienzation. Harvard Educational Review 40: 452-477.

Freire, P. 2000. Pedagogy of the oppressed. New York: Continuum International.

Gee, J. 1996. Social linguistics and literacies: Ideology in discourses. London: Rutledge.

Gee, J. 2008. A social and situated account. In Literacies, global and local, ed. Prinsloo M, Baynham M. 137-149. Philadelphia: John Benjamins.

Goodman, K. 1987. Language and thinking in school: A whole-language curriculum. New York: RC Owen.

Hartman, DK. 1995. Eight readers reading: The intertextual links of proficient readers reading multiple passages. Reading Research Quarterly 30: 520-561.

International Reading Association. 2002. Summary of the (U.S.) national reading panel report: Teaching children to read. Washington, DC: U.S. Government Printing Office.

Johnson, M. 2004. A philosophy of second language acquisition. New Haven, CT: Yale University Press.

Kim, D. 2009a. Asian American students' second-language literacy development in engaging literacy events. In New perspectives on Asian American parents, students, and teacher recruitment, ed. Park C, Endo R, Rong XL. 80-111. Northridge, CA: Information Age.

Kim, D. 2009b. Using sociocultural perspectives of literacy and culturally relevant pedagogy to empower beginning ELLs as readers. English Leadership Quarterly 31(3): 9-11.

Kim, D. 2011. A young English learner's L2 literacy practice through dialogue journal. Journal of Reading Education 36(1): $27-34$.

Koda, K. 2007. Reading and language learning: Crosslinguistic constraints on second language reading development. Language Learning 57: 1-44.

Krauss, SE. 2005. Research paradigms and meaning making: A primer. The Qualitative Report 10: 758-770.

Lave, J, and W Wenger. 1991. Situated learning. Legitimate peripheral participation. Cambridge, UK: University of Cambridge Press.

Lederach, JP. 1995. Preparing for peace: Conflict transformation across cultures. Syracuse, NY: Syracuse University Press.

Lincoln, YS, and EG Guba. 1985. Naturalistic inquiry. London: Sage.

McElvain, CM. 2010. Transactional literature circles and the reading comprehension of English learners in the mainstream classroom. Journal of Research in Reading 33: 178-205.

Merriam, SB. 1998. Qualitative research and case study applications in education. San Francisco, CA: Jossey-Bass.

Mortimer, EF, and PH Scott. 2003. Meaning making in secondary science classrooms. Buckingham, UK: Open University Press.

Nassaji, H. 2007. Schema theory and knowledge-based processes in second language reading comprehension: A need for alternative perspectives. Language Learning 57: 79-113.

National Institute of Child Health and Human Development. 2000. Report of the National Reading Panel, Teaching children to read: An evidence-based assessment of the scientific research literature on reading and its implications for reading instruction (NIH Publication N. 00-4769). Washington, DC: U.S. Government Printing Office.

Olson, K. 2007. Lost opportunities to learn: The effects of education policy on primary language instruction for English learners. Linguistics and Education 18(2): 121-141, Doi:10.1016/j.linged.2007.07.001.

Pacheco, M. 2010. English-language learners' reading achievement: Dialectical relationships between policy and practices in meaning-making opportunities. Reading Research Quarterly 45(3): 292-317.

Park, H-R, and D Kim. 2011. Reading-strategy use by English as second language learners in online reading tasks. Computers and Education 57(3): 2156-2166.

Peregoy, SF, and OF Boyle. 2008. Reading, writing, and learning in ESL: A resource book for teaching K-12 English learners. Boston: Pearson, 5.

Perez, B. 1998. Sociocultural contexts of language and literacy. Mahwah, NJ: Erlbaum.

Pray, L, and R Jimenez. 2009. A response to "Literacy and English language learners: A shifting landscape for students, teachers, researchers, and policy makers," by Jim Cummins. Educational Researcher 38(5): 384-385.

Pressley, M, and P Afflerbach. 1995. Verbal protocols of reading: The nature of constructively responsive reading. Hillsdale, NJ: Erlbaum.

Rosenblatt, LM. 1978. The reader, the text, the poem: The transactional theory of the literary work. Carbondale: Southern Illinois University Press.

Rosenblatt, LM. 1986. The aesthetic transaction. Journal of Aesthetic Education 20(4): 122-128.

Rosenblatt, LM. 1993. The transactional theory: Against dualisms. College English 55: 377-386.

Stern, HH. 1983. Fundamental concepts of language teaching. Oxford: Oxford University Press.

Uebel, M. 2007. B(eing)-students. Journal of Narrative Theory 37(2): 326-348. 
Vygotsky, LS. 1978. Interaction between learning and development. In Mind in society: The development of higher psychological processes, ed. Vygotsky LS, Cole M, John-Steniner V, Scribner S, Souberman E. 79-91. Cambridge, MA: Harvard University Press.

Weaver, C. 2002. Reading process and practice. Portsmouth, NH: Heinemann.

Wells, G. 2007. The mediating role of discoursing in activity. Mind, Culture, and Activity 14: 160-177.

Windschitl, M. 2000. Constructing understanding. In Cultures of curriculum, ed. Joseph PB, Bravmann SL, Windschitl MA, Mikel ER, Green NS. 95-136. Mahwah, NJ: Erlbaum.

Yamashita, J. 2002. Mutual compensation between L1 reading ability and L2 reading proficiency in L2 reading comprehension. Journal of Research in Reading 25: 81-95.

doi:10.1186/10.1186/2191-5059-1-2

Cite this article as: Kim: Dialogic meaning construction and emergent reading domains among four young

English language learners in second-language reading. Multilingual Education 2011 1:2.

\section{Submit your manuscript to a SpringerOpen ${ }^{\circ}$} journal and benefit from:

- Convenient online submission

- Rigorous peer review

- Immediate publication on acceptance

- Open access: articles freely available online

- High visibility within the field

- Retaining the copyright to your article

Submit your next manuscript at $\gg$ springeropen.com 